\title{
Mons. Gerardi, obispo mártir en una Iglesia mártir*
}

\author{
Santiago Otero, \\ Universidad Rafael Landívar, \\ Guatemala.
}

Mons. Gerardi es el obispo de la paz y el mártir de la paz. Su muerte ocurrió el 26 de abril de 1998 en el garaje de su casa parroquial de San Sebastián, ciudad de Guatemala, dos días después de la presentación del Informe REMHI. Informe en el que se contempla la realidad de un pueblo martirizado, y la realidad de una iglesia mártir. "El obispo que rompió el silencio", como lo han caracterizado otras personas ${ }^{1}$. La Iglesia guatemalteca, desde sus obispos hasta el más humilde de los catequistas de la aldea más apartada, ha sido la más golpeada de América Latina en los últimos cuarenta años. Son muchos los catequistas, sacerdotes, religiosas, obispos, que han sido golpeados por la causa del Reino de Dios, y han entregado su vida como Jesús, al servicio del Evangelio y de sus comunidades $^{2}$. En este contexto, monseñor Juan José Gerardi Conedera ha sido una víctima más, a quien se ha reconocido como mártir de la verdad y de la paz, mártir de los derechos humanos, en una Iglesia mártir.

* En esta revista hemos publicado artículos teóricos sobre el martirio y artículos histórico-testimoniales sobre mártires: Rutilio Grande, Christophe Munzihirwa, Dietrich Bonhoeffer, Alfred Delp. Publicamos ahora, en el XX aniversario de los mártires de la UCA, este artículo sobre el mártir monseñor Juan José Gerardi Conedera, considerado como uno de los Padres de la Iglesia Latinoamericana.

1. M. Carrera, Juan Gerardi. Il vescovo che ruppe il silenzio, Milano, 2008. Que es la traducción de la segunda edición castellana titulada En la mirilla del jaguar. Biografía novelada de monseñor Gerardi, FCE, Guatemala, 2002 y la segunda edición en 2005.

2. Conferencia Episcopal de Guatemala, Testigos fieles del evangelio, Guatemala, marzo 2007. Esta edición fue publicada con ocasión de la V Conferencia General del Episcopado Latinoamericano y del Caribe en Aparecida, Brasil, en 2007. Nos ofrece la narración breve del testimonio (martirio) de muchos laicos, catequistas, directivos de Acción Católica, Delegados de la Palabra o Animadores de la Fe, junto al de varios sacerdotes y misioneros, una religiosa y un obispo. 
Esto es lo que contempló el papa Juan Pablo II cuando visitó Guatemala en marzo de 1983, y un año después les recordara a los obispos guatemaltecos, en una bella carta:

Entre los casos de injusticia y de violencia que continúan dándose aún en vuestro país he de recordar el drama de los desaparecidos y la plaga de secuestros de personas. Es este un uso inhumano que ha vestido de luto a tantas familias o que las deja en una angustiosa incertidumbre. La gravedad y crueldad de estos innobles delitos es aún mayor cuando se cometen contra personas inocentes con fines intimidatorios o de represalia.

No puedo dejar de recordar que entre las víctimas de la violencia y del odio se encuentran innumerables evangelizadores de la cruz y de su mensaje de caridad: sacerdotes, religiosos y religiosas, y sobre todo, ministros de la Palabra. Cuando la historia más reciente de vuestra Iglesia sea presentada a las generaciones futuras, ¿será posible dar a conocer en sus páginas la larga lista de nombres de tantos catequistas, generosos sembradores de la Palabra de Dios, que en el cumplimiento de su misión cayeron víctimas del odio fratricida? ${ }^{3}$

\section{Un obispo en medio del enfrentamiento armado}

Monseñor Juan Gerardi fue asesinado el domingo 26 de abril de 1998, en su propia residencia de la Parroquia de San Sebastián, a eso de las diez de la noche cuando regresaba de visitar a sus familiares, hermana y sobrinos. Dos días antes, en la Catedral Metropolitana de Guatemala se había presentado el Informe Interdiocesano para la Recuperación de la Memoria Histórica, en el que se denunciaban las graves violencias del enfrentamiento armado interno que abarcaba 36 años de guerra, de 1960 a 1996. Un crimen que enmudeció a la sociedad guatemalteca, un hecho que prolongaba la impunidad, eje de las políticas del terror con el que los diversos regímenes militares, unos golpistas y otros fraudulentos, se fueron imponiendo por la vía de la fuerza.

Este crimen ponía en entredicho los acuerdos de paz que se habían firmado el 29 de diciembre de 1996, proceso que había durado unos diez años, en diferentes etapas, y en los que participó muy decididamente la Iglesia Católica, que desde los años del Concilio había venido reiteradamente denunciando las injusticias, sobre todo la que nacía de la injusta distribución de los bienes, principalmente la tierra ${ }^{4}$, así como las graves limitaciones impuestas a la participación ciudadana de la sociedad civil, en años en los que las organizaciones campesi-

3. Carta del papa Juan Pablo II al episcopado guatemalteco, 2 de diciembre de 1984, 1 er Domingo de Adviento. En Conferencia Episcopal de Guatemala, Al servicio de la vida, la justicia y la paz, Documentos de la CEG 1956-1997, Guatemala, 1997, pp. 853-854.

4. T. Melville y M. Melville, Tierra y poder en Guatemala, Editorial Universitaria Centroamericana, San José, 1975. 
nas - sobre todo indígenas - y obreras reclamaban sus derechos a un nivel de vida más equitativo y al respeto de la dignidad de la persona humana. Derechos que se fundamentaban en la Enseñanza Social de la Iglesia, sobre todo a partir de la Pacem in Terris, la Gaudiun et Spes, la Populorum Progressio, Medellín, Puebla... La búsqueda de una paz firme y duradera fue tomando forma a raíz de los Acuerdos de Esquipulas ${ }^{5}$, donde los presidentes centroamericanos reunidos tomaron el compromiso institucional de iniciar procesos de paz que llevaran a las sociedades de sus respectivos países a la reconciliación, fundamentada en la verdad y la justicia.

La Conferencia Episcopal de Guatemala aceptó el reto de acompañar este proceso en un país donde la mayoría de la población es pobre, y un $60 \%$ indígena. Monseñor Rodolfo Quezada Toruño fue nombrado presidente de la Comisión Nacional de Reconciliación y monseñor Juan José Gerardi, su colaborador directo, suplente de la misma, junto a un grupo de dignatarios políticos más ${ }^{6}$. Sin embargo, este marco tan general debe ser profundizado para llegar a desentrañar la rica personalidad de monseñor Juan Gerardi.

\section{Juan Gerardi, hijo de una familia de emigrantes}

Los regímenes liberales del siglo XIX en Guatemala promovieron políticas favorables para que inmigrantes europeos, que pudieran labrar sus fértiles tierras, llegaran al país. Junto a humildes campesinos belgas, franceses, alemanes e italianos, también se instalaron otros sectores que promovieron explotaciones agrícolas que pudieran vincular la débil economía guatemalteca con el mercado internacional. En este proceso la historia da cuenta de éxitos y grandes fracasos.

Domenico Girardi, con su esposa y tal vez cuatro hijos todavía niños, campesinos pobres del entorno de la ciudad de Trento, entonces bajo el imperio austro-húngaro, dejando atrás sus tierras, familia y tradiciones, se embarcaron

5. Esquipulas es el santuario donde se venera al Santo Cristo Negro de Esquipulas, ciudad limítrofe de Guatemala, cercana a El Salvador y Honduras, cuya devoción popular se enraíza en el siglo XVI, donde se venera una bella imagen del Señor Crucificado, obra del escultor Quirio Cataño, que la entregó en 1596, y cuyas resonancias autóctonas de tiempos pretéritos son evidentes. La Gran Basílica actual, terminada de construir hace 250 años, en 1759, es un centro de peregrinación mesoamericano, sobre todo de los pueblos guatemaltecos, salvadoreños y hondureños, y que se construyó con el aporte de los fieles de todas las parroquias del llamado antiguo Reino de Guatemala. Actualmente, es prelatura y está administrado por una comunidad benedictina.

6. Monseñor Rodolfo Quezada, en aquel entonces, 1987, era obispo de la diócesis de Zacapa, y monseñor Juan Gerardi era obispo auxiliar de Guatemala y secretario general de la Conferencia Episcopal de Guatemala. Desde 2001, monseñor Quezada fue nombrado arzobispo de la Arquidiócesis de Guatemala, hecho cardenal por Juan Pablo II en el Consistorio de 2003. 
hacia América, para probar fortuna en Brasil o Argentina ${ }^{7}$. La realidad fue muy otra, pues el barco los dejó en el puerto de Santo Tomás de Castilla, en tierras guatemaltecas, en una región inhóspita, después de 1875. Como el barco en el que viajaban les negó cupo para América del Sur, y viéndose en la terrible situación de sobrevivir en el trópico y con sus hijos pequeños, decidieron viajar a Guatemala, que en aquel tiempo era un largo trecho a pie o en mulas, sin más esperanza que encontrar un trabajo que les permitiera vivir. Se instalaron en uno de los barrios más populares de la ciudad de Guatemala, donde también se encontraron con otras familias italianas. Todavía nacieron dos hijos más. El menor de ellos, Benito, contrajo matrimonio con Laura Conedera, con quien procreó a cuatro vástagos, de los cuales el segundo, Juan José Gerardi, nació en la ciudad de Guatemala el 27 de diciembre de $1922^{8}$.

En esa época, la Iglesia guatemalteca pasaba por el calvario purificador de la persecución liberal, que desde 1871 decretó la expulsión del arzobispo y obispo auxiliar de Guatemala, una sola diócesis, la expulsión de los jesuitas y resto de congregaciones masculinas, sobre todo dominicos, franciscanos, capuchinos... la exclaustración de los conventos de órdenes femeninas, todas contemplativas. Solo quedaron las Hermanas Hijas de la Caridad y los Padres Paulinos (vicentinos), que apenas llevaban en el país diez años. De 1871 a 1928, la Iglesia de Guatemala fue probada reiteradamente, perdió todas sus posesiones, se quedó sin clero y congregaciones religiosas, y proscribieron las manifestaciones religiosas de carácter público. En este mismo tiempo, casi sesenta años, la Arquidiócesis permaneció sin obispo residente unos treinta años. El clero autóctono era escaso, las parroquias rurales se quedaron sin atención religiosa y muchos de los edificios de la Iglesia pasaron a manos del Gobierno. Cuando nació Juan Gerardi, el arzobispo había sido expulsado del país, y no sería sino hasta noviembre de 1928 que la Santa Sede divide a Guatemala en dos diócesis y nombra un nuevo arzobispo, en la persona de un religioso paulino francés, Luis Durou y Sire, y el primer obispo para la diócesis recién formada de los Altos de Quetzaltenango, Mons. Jorge García y Caballeros. Hay que añadir que en estos períodos se sucedieron diversos Gobiernos liberales, todos militares, y algunos períodos de dictadura prolongada, como los de Justo Rufino Barrios (1873-1885), Manuel Estrada Cabrera (1898-1920) y Jorge Ubico (1931-1944), sin hacer mención de otros más que se sucedieron en lapsos más breves.

En esta misma coyuntura, la población guatemalteca pasó de, aproximadamente, 1,500,000 habitantes en 1900 a 3.5 millones en 1950, y a 12 millones en 2000. Las familias campesinas vivían en los pueblos de las montañas de Guatemala, carentes de tierra, y ofreciendo su mano de obra barata en las fin-

7. El apellido "Girardi" del entorno de Trento, al llegar a Guatemala, se transformó en "Gerardi".

8. Cfr. S. Otero Diez, Gerardi, memoria viva, Guatemala, 2008. 
cas de café, banano... de las regiones más fértiles del país que fueron cayendo en manos de terratenientes, y sobre todo de la United Fruit Company (UFCO). Monseñor Gerardi todavía conoció en sus años como obispo de la diócesis de Quiché, cómo se bajaba a la costa a cientos de familias indígenas para realizar las labores de las cosechas.

Antes de 1940, la Iglesia guatemalteca no contaba con un seminario bien constituido; la Compañía de Jesús se había encargado del seminario menor a partir de 1937, donde los seminaristas que terminaban humanidades, latín y filosofía continuaban los años de teología en el Seminario San José de la Montaña de San Salvador. Sin embargo, a Juan Gerardi se le envió al seminario de Nueva Orleans en Estados Unidos. Todos sus compañeros recuerdan la memoria impresionante que tenía. Fue ordenado sacerdote por el arzobispo Mariano Rossell Arellano en Guatemala, en 1946, y a partir de esta fecha desempeñó diversos cargos de párroco en pueblos rurales de la Arquidiócesis y otros servicios administrativos; siendo canciller de la curia, Pablo VI lo nombra obispo de la diócesis de Verapaz, en 1967. Era una iglesia pobre, fundamentalmente de población q'eqchí, de profunda religiosidad, con poco clero y difíciles comunicaciones entre sus pueblos. Juan Gerardi ya conocía la realidad del mundo indígena y campesino, pero fue en su sede de la ciudad de Cobán donde empezó a profundizar en la realidad de vida del pueblo, pues ahí había sido enviado como obispo y pastor. Hizo un gran esfuerzo por aprender la lengua del lugar, y dio los primeros pasos para organizar pastoralmente una diócesis de acuerdo a la dinámica pastoral propuesta por el Concilio Vaticano II. De este objetivo da cuenta su primera carta pastoral, titulada "Diócesis, comunidad viva y operante. A la luz del Vaticano II", del 30 de julio de 1968. Como obispo joven y entusiasta, asumió con prontitud y energía las propuestas doctrinales y pastorales para su iglesia de Verapaz. La pastoral de conjunto, la constitución de los Delegados de la Palabra de Dios, la radio, la dotación de clero joven a la diócesis, la promoción de la pastoral indígena y social fueron objetivos muy claros de su ministerio episcopal.

Si bien los tiempos habían cambiado, la Iglesia en Guatemala no gozaba de tiempos propicios: crecimiento de la población, pero pocos agentes de pastoral; prolongación de los Gobiernos militares; golpes de Estado; y limitaciones incesantes a la actividad pastoral de la Iglesia. Sí es importante destacar que los Gobiernos liberales que fueron de 1871 a 1944 no pudieron lograr, en más de setenta años, institucionalizar la democracia en el país, que tuvo un tiempo privilegiado de 1944 a 1954, con el que un golpe de Estado dio fin a la llamada primavera democrática, época a la que siguieron Gobiernos de corte militar. De 1871 a 1986, más de un siglo, Guatemala sólo conoce dos Gobiernos civiles 9 .

9. V. Melander, The hour of God? People in Guatemala confronting political evangelicalism and counterinsurgency (1976-1990), Uppsala, 1999. 


\section{La Iglesia toma posición ante la realidad}

Hacia 1946, en Guatemala no se contaban ni cien sacerdotes en activo para atender a todas las parroquias del país. Juan Gerardi era uno de ellos. Sufrió el acoso constante de las políticas liberales de corte anticlerical. Un liberalismo anquilosado que se fue transformando en "conservador" dando muchas facilidades a los pocos sectores muy pudientes de la sociedad guatemalteca. La fuerza política y económica de la Iglesia era insignificante; no así la social, pues su credibilidad moral había permanecido a pesar de los golpes del liberalismo, y la figura del arzobispo Mariano Rossell, verdadero organizador de la Iglesia en Guatemala en el siglo XX (1939-1964), logró un liderazgo social que aglutinó un capital simbólico en el que se sentían representados los guatemaltecos; esto la llevó a apoyar el golpe de Estado de 1954, porque había interpretado en el régimen del coronel Jacobo Arbenz Guzmán una manifiesta tendencia comunista que amenazaba la nacionalidad guatemalteca y las mismas tradiciones religiosas y culturales de Guatemala.

Aun antes del Concilio, en 1962, la Iglesia guatemalteca, que poco a poco se fue constituyendo en Conferencia Episcopal, con la creación de nuevas diócesis en las décadas de los años cincuenta y sesenta, denuncia que la amenaza del comunismo que había advertido diez años antes no tenía otra causa que la injusticia social, la marginación del mundo campesino e indígena, y la injusta distribución de las riquezas. Fue así como la Iglesia en Guatemala apostó por una presencia muy activa en el mundo de los más pobres; promovió las cooperativas, las organizaciones comunales y campesinas; y apoyó en el mundo indígena los programas de educación, alfabetización, salud y organización cívica. Promovió la concientización del pueblo y les enseñó a luchar para conseguir hacer respetar sus propios derechos. La dinámica del Concilio, la fuerza de la Conferencia de Medellín, y la llegada al país de un contingente de misioneros que tomaron profunda conciencia de la realidad de injusticia en la que vivía el pueblo de Guatemala, fue determinante. Sectores del pueblo habían asumido otras opciones, y no faltaron las ideologías liberales decimonónicas, que postulaban una oposición a los programas de la Iglesia más por motivos ideológicos y doctrinarios que por la realidad que contemplaban en proceso de transformación. Sectores de poder tradicionales, sobre todo económicos, nunca vieron bien la obra social de la Iglesia; del mismo modo, los sectores de la izquierda revolucionaria tardaron mucho en entender la misión pastoral y social de la misma Iglesia. Sí es importante destacar que a partir de los años setenta la confrontación de la Iglesia con las fuerzas militares del país se fue haciendo cada vez más notoria, en la medida en que el pueblo era víctima de las violaciones más salvajes contra la dignidad de la persona humana y los derechos sociales y políticos de la población.

La falta de participación política de la sociedad civil, la imposición de Gobiernos militares, la constante violación de los derechos de los pueblos indígenas, 
campesinos y obreros fueron creando las condiciones del nacimiento de la insurgencia armada revolucionaria, que fue la contraparte del conflicto armado interno de 1960 a 1996. Si bien la Iglesia nunca apoyó el proceso revolucionario de la transformación social, coincidía con el movimiento insurgente en señalar sus verdaderas raíces políticas y sociales, la falta de justicia social y la negación del valor de la vida en cada ser humano. Con los fraudes electorales de 1970, 1974 y 1978, muchos sectores sociales se unieron a la insurgencia revolucionaria, y con ellos muchos cristianos que en virtud de su fe habían alcanzado un nivel suficiente de indignación que no les permitía contemplar pasivamente aquella situación.

\section{Monseñor Juan Gerardi en la diócesis de Quiché}

Cuando monseñor Gerardi llegó a la diócesis de Quiché (diciembre de $1974)^{10}$, en el corazón norte de Guatemala, la realidad del conflicto estaba generalizada. En su diócesis tenía pocos agentes de pastoral, sacerdotes y religiosas; desde 1954 estaba encomendada casi en su totalidad a los Misioneros del Sagrado Corazón, que desplegaron verdaderos programas pastorales y sociales de transformación de la realidad. La población del Quiché era mayoritariamente indígena y pertenecía a grupos lingüísticos bien diferenciados: K'iche’s, q'eqchíes, ixiles y algunas otras comunidades. Se encontró, sin embargo, una iglesia bastante organizada, con un contingente grande de catequistas formados al estilo de la Acción Católica de los años cincuenta, verdaderamente comprometidos con su fe, solidarios y con un gran empuje pastoral, social y político. Los catequistas eran verdaderos agentes de iglesia, con gran liderazgo dentro de las comunidades campesinas e indígenas, bastante bien formados y, sobre todo, organizados. Las cooperativas habían constituido un modo muy efectivo para organizar a los campesinos y promover sus derechos. Pronto chocaron con ciertos sectores de poder. A pesar de todo, el pueblo del Quiché, que monseñor Gerardi contemplaba en sus visitas pastorales a las parroquias, era verdaderamente pobre.

Antes de llegar a Quiché, la vida de monseñor Gerardi había tenido cuatro momentos determinantes que incidirían en su trabajo pastoral: (a) en 1968 participó en la Conferencia de Melgar, Colombia, del Departamento de Misiones del CELAM; (b) con sólo cinco años de ser obispo, la Conferencia Episcopal (CEG) lo elige presidente de la misma en $1972^{11}$; (c) en 1974 es delegado al sínodo de la evangelización en Roma, que fue determinante para su labor pastoral; y (d) ya

10. Cfr. Diócesis del Quiché, El quiché, el pueblo y su iglesia, Santa Cruz del Quiché, 1974.

11. Ningún obispo en Guatemala fue tan joven (49 años) presidente de la Conferencia Episcopal de Guatemala y ningún otro fue elegido tantas veces (tres) al mismo cargo. Monseñor Gerardi asistió a dos sínodos en Roma: 1974 y 1980. Fue elegido también para participar en la Conferencia de Puebla en 1979. 
estando en Quiché, su presencia en la reconstrucción de los pueblos destruidos en el terrible terremoto del 4 de febrero de 1976.

Su participación en Melgar fue determinante para iniciar en La Verapaz y en Quiché verdaderos proyectos pastorales "inculturados", que tuvieran en cuenta la promoción de la evangelización en sintonía con la realidad de los pueblos, sobre todo con su cultura y aspiraciones de vida. Fue en este encuentro donde conoció a monseñor Samuel Ruiz, obispo de Chiapas, con años de experiencia pastoral, y como él, en una diócesis indígena. La visión de monseñor Gerardi cambió de manera determinante; quedaba atrás el buen y cumplido administrador de curia. En segundo lugar, el hecho de haber sido elegido presidente de la CEG lo colocaba en un puesto de responsabilidad y mediación al interior de la misma Iglesia, lo que nos muestra algunos rasgos de la personalidad de monseñor Gerardo: comedido, prudente, responsable, equilibrado, ajeno a las ideologías, muy consciente de la realidad; y esto en años en los que la CEG tuvo serios problemas para mantener la unidad visible e institucional. En el sínodo sobre la evangelización monseñor Gerardi fue relator de un grupo de obispos de lengua española; fue un momento privilegiado en su vida que le abrió a la dimensión mayor de la Iglesia universal, de sus problemas, y sobre todo, de la presencia de la Iglesia latinoamericana en el sínodo. El papa Pablo VI había quedado impactado al ver la realidad de los pobres en su visita a Bogotá en 1968. En la exhortación Evangelii Nuntiandi (1975), aparecen estos rasgos con claridad. En el vocabulario de monseñor Gerardi irrumpen con fuerza las palabras "evangelización", "liberación", "religiosidad del pueblo", "injusticia institucionalizada"... Medellín y la tradición reciente de la Iglesia latinoamericana resonaban con fuerza en este documento pontificio; no por nada va a constituir la base y la fuerza de la Iglesia más comprometida con la realidad y la liberación de los pobres que se reúne en Puebla a principios de 1979, y donde también estará monseñor Juan Gerardi.

Con el terremoto de 1976, contempla impotente la Guatemala de los más pobres hundida en la destrucción y la desolación. Un fenómeno natural que dejaba al descubierto la verdadera radiografía de las grandes diferencias sociales que ensombrecen la realidad guatemalteca. Tal vez todos padecieron algo, pero los más pobres sufrieron en extremo. La Iglesia se hizo inmediatamente presente en la reconstrucción, pero unieron al proceso material la iluminación pastoral y teológica, publicando una importante carta pastoral titulada "Unidos en la Esperanza" (julio de 1976) ${ }^{12}$, una verdadera denuncia de las injusticias sociales, en cuya elaboración y publicación tuvo mucho que ver monseñor Gerardi, entonces presidente de la CEG. Este documento presenta a la Iglesia de Guatemala con el

12. Conferencia Episcopal de Guatemala, Al servicio de la vida, la justicia y la paz, óp. cit. El señor cardenal de entonces decidió no firmar dicho documento; se encontraba en un viaje fuera de Guatemala. 
rostro que ha tratado de mantener en los últimos 35 años: una Iglesia comprometida con la vida de los pobres, que hace opción por los pobres, que lucha contra las injusticias, que se enfrenta a la militarización del país, que denuncia los salarios de hambre de campesinos y trabajadores, que ofrece esperanza a los más humildes, que les ofrece su total apoyo. La Iglesia dejaba de ser indiferente o disimular ciertas realidades en abierta contradicción con el Evangelio. El orden debe ir acompañado de la justicia para conseguir la paz. No cabe la menor duda de que monseñor Gerardi formaba parte de esta Iglesia más comprometida. Su pensamiento estaba firmemente marcado por la huella del Concilio, lo había asumido en su estilo de iglesia, en su proyecto pastoral y, sobre todo, en su espiritualidad en la configuración y construcción de comunidades vivas y operantes ${ }^{13}$.

\section{Monseñor Gerardi confrontado con el terror del Estado}

Monseñor Juan Gerardi sabía muy bien que la Iglesia que asume la causa de un pueblo, como lo señalaba el Concilio en el primer número de la Constitución pastoral Gaudium et Spes, se expone a sufrir las mismas consecuencias que padece la gente. Y la Iglesia en Guatemala pasó también por este trance. Esta afirmación debe ser comprendida en toda su profundidad.

Cuando monseñor Juan Gerardi llegó a Quiché, dedicó un tiempo a conocer la diócesis y a tomar contacto con todas sus fuerzas vivas, analizar proyectos y evaluar la presencia de la Iglesia en cada parroquia. La pastoral estaba fuertemente marcada por la dinámica de Acción Católica y la propuesta de los Misioneros del Sagrado Corazón, que en un momento dado llegaron a ser 28.

Hubo, sin embargo, dos acontecimientos ya mencionados que golpearon fuertemente el corazón de Gerardi: el primero, el terremoto que destruyó varios pueblos de la diócesis, con saldo de miles de damnificados; sin reponerse de este golpe, monseñor Gerardi contempla ante sí la realidad de la militarización completa del departamento de Quiché, que coincide con los límites de su misma diócesis, aunque el hecho en sí tiene otros puntos álgidos a lo largo y ancho del país, sobre todo en el altiplano indígena. En Quiché la violencia ejercida por las instituciones estatales, principalmente el Ejército, llegó a grados extremos, sobre todo a partir de 1979. El entusiasmo con el que regresaba monseñor Gerardi de Puebla se encontraba con un revés ineludible. De todos modos, inició un proceso pastoral para elaborar un plan diocesano acorde con la visión espiritual, pastoral y teológica nacida en Puebla. No lo pudo ver realizado. Los acontecimientos de violencia se fueron imponiendo de manera implacable. La violencia de la insurgencia también golpeaba en la misma realidad, pero de manera selectiva.

13. Conferencia Episcopal de Guatemala, Monseñor Juan Gerardi, testigo fiel de Dios, La Nueva Guatemala de la Asunción, 1999 (1. er aniversario). 
De acuerdo a los principios de la doctrina de la seguridad nacional, los Gobiernos militares de la época impusieron a la sociedad civil la organización paramilitar conocida como "patrullas de autodefensa civil" en cada pueblo y aldea. Era el pueblo armado contra sí mismo. Constituía la institucionalización de la violencia en la realidad capilar de la sociedad, en sus estratos más sensibles del tejido social, hasta llegar a la familia.

¿Qué respuesta podía dar la diócesis de Quiché a esta generalización de violencia? Monseñor Gerardi siempre abogó por la cordura, el diálogo, la reflexión, el sentido de humanidad. Pero los acontecimientos se iban imponiendo como martillazos contra la paz. El 31 de enero de 1980 un grupo de campesinos y estudiantes, en su mayoría de Quiché, tomaron pacíficamente la embajada de España en la ciudad de Guatemala. La respuesta del Gobierno militar del general Lucas García no permitió ningún tipo de diálogo. Contra todo derecho internacional invadió las instalaciones de la sede diplomática europea, donde murieron quemadas 39 personas, entre diplomáticos, campesinos y estudiantes. Monseñor Gerardi, con los agentes de su diócesis, respondió con un comunicado condenando la acción. De este modo, empezaba a ser no sólo acusado, sino señalado de permitir que la Iglesia justificara la violencia revolucionaria. En su diócesis se fueron sucediendo los secuestros de campesinos, de catequistas, la persecución de sacerdotes y religiosas. En abril fue bombardeado el convento de la parroquia de Uspantán en su diócesis; toda la zona norte de Quiché se iba despoblando de agentes de pastoral. En mayo, en la prelatura de Escuintla son asesinados dos misioneros CICM; el 4 de junio de ese mismo año, después de una gira misionera, fue asesinado cerca de la parroquia de Chajul, en Quiché, el sacerdote José María Gran, MSC, y su sacristán Domingo del Barrio Batz; el 10 de julio de ese mismo año, en la parroquia de Joyabaj, fue asesinado el sacerdote Faustino Villanueva, también MSC. La persecución contra la Iglesia se había generalizado $^{14}$. A estos y otros muchos hechos de violencia, monseñor Gerardi respondía con la cordura necesaria, que no le faltaba, pero también con vehemencia, condenando los atropellos contra la dignidad de la persona humana. En esta coyuntura se descubre que el Gobierno ha decidido acabar con la Iglesia de Quiché. Monseñor Gerardi y los pocos agentes que todavía le quedaban en la diócesis deciden en una reunión que, por el bien de los catequistas y líderes laicos, era mejor retirarse un tiempo del distrito. Esta decisión le costó dolor y lágrimas a monseñor Gerardi, pero también la pena moral de sentirse como el pastor que se ausenta de su rebaño. Él no quería que su presencia en la diócesis fuera la disculpa de matanzas, o que hiciera pensar que la Iglesia animaba a las fuerzas subversivas.

14. Sobre los mártires del Quiché, la diócesis ha publicado dos libros: (1) Dieron la vida, Santa Cruz del Quiché, 2003 (el autor de la obra es el P. Jesús Lada Camblor, MSC);

(2) Dieron la vida, vol. II: Libro de los Mártires de la Diócesis de Quiché, Ediciones San Pablo, Guatemala, 2003. 
En repetidas ocasiones monseñor Gerardi se acercó con temor y temblor a las autoridades políticas y militares para llamar a la cordura, el cese de la represión y el respeto a la vida de la gente que diariamzpetida. Les manifestaba que la guerrilla crece no porque la ideología de la gente cambia, o porque de un día para otro todos amanezcan siendo "comunistas", sino por la represión y el terror que provoca el Ejército en toda la población. Aun cuando en la región de Quiché el Gobierno ya tenía decidida su estrategia, se atrevieron a solicitarle a monseñor Gerardi su colaboración más o menos en estos términos: "Si la Iglesia quiere la paz y la tranquilidad, ¿por qué no colabora con nosotros?”. Monseñor Gerardi, sin pensarlo mucho, fue enfático en su respuesta: "Mientras el Ejército siga matando campesinos, y sembrando de luto y dolor los campos de mi diócesis, eso nunca será posible".

Monseñor Gerardi aceptaba dejar la diócesis con todos sus agentes, manteniendo contacto con los catequistas y las comunidades cristianas casi de manera clandestina, algo así como él se movió en la ciudad de Guatemala durante un mes, antes de salir para Roma para comunicar al Santo Padre la situación que se había creado en su diócesis; la ocasión también se la daba la asistencia al sínodo sobre la familia en Roma, del otoño de 1980. Fue recibido por el papa Juan Pablo II al menos en dos ocasiones. En la primera, el papa escuchó atentamente la narración de los hechos acaecidos en la diócesis de monseñor; el papa le rogó que a pesar de todo convenía que regresara a Quiché. Bien conocía Juan Pablo II de persecuciones. Pero, ¿cómo hacerlo en aquellas circunstancias? El papa estuvo de acuerdo que tal situación de persecución de la Iglesia debía ser denunciada, y él mismo apoyaría dicha solución. En dos reuniones más, que se debieron dar mientras el sínodo se desarrollaba de acuerdo a su programa, se concluyó una bella carta que el papa Juan Pablo II envió al episcopado guatemalteco, con fecha del uno de noviembre de ese mismo año. El día anterior habían tenido la última reunión juntos, sin duda para que monseñor Gerardi le indicara si estaba de acuerdo con su contenido. Era una carta fuerte, que llegada desde Roma señalaba directamente a los verdaderos responsables de la persecución de la Iglesia. Los obispos guatemaltecos decidieron hacerla pública, aunque el señor cardenal de Guatemala vio oportuno dar a conocer su contenido al presidente de la República, el general Romeo Lucas García. Cuando el militar la leyó, intuyó inmediatamente que detrás de su contenido estaba la mano de monseñor Gerardi. Fue en ese momento que se le escapó una expresión llena de rabia: "Si ese cura entra en Guatemala, nos lo tronamos". La sentencia de muerte de monseñor Gerardi ya no necesitaba redactarse.

Cuando por fin el 20 de noviembre de 1980 regresaba vía aérea monseñor Gerardi a su país, las autoridades de migración le impidieron la entrada. De nada valió la oportuna intercesión del encargado de negocios de la Nunciatura Apostólica ni la presencia de varios obispos de la conferencia episcopal. Mon- 
señor Gerardi debió viajar esa misma noche a El Salvador, donde tampoco pudo permanecer por muchas horas, pues el presidente de la República, Napoleón Duarte, demócrata cristiano, le hizo saber al obispo que tampoco él podía garantizar su seguridad en el país. Continuó su viaje hasta Costa Rica, donde fue recibido primero en la Nunciatura y luego en una parroquia de las afueras de San José, San Juan de Tibás. Se expulsaba del país a un obispo que era Presidente de la Conferencia Episcopal. Fue su exilio forzado. Tampoco podía cumplir el deseo del papa. Para Quiché, el Vaticano nombró dos administradores apostólicos sucesivos. Pero hacia 1983, casi la totalidad de las casas parroquiales de la diócesis, centros de formación, colegios católicos, sede de Cáritas, internado de varones habían sido intervenidos por el Ejército, muchos de ellos convertidos en bodegas de pertrechos de guerra. Una periodista norteamericana, que pudo hacer algunos reportajes en aquellas circunstancias en tierras de Quiché, publicó fotos de las iglesias tomadas por militares; en una de esas fotos se ve a los santos de la iglesia de Chajul vestidos con uniformes militares ${ }^{15}$.

\section{Del exilio a la lucha por los derechos humanos}

Año y medio permaneció monseñor Gerardi en esta situación, viviendo como un vicepárroco. En estos años revivía el viacrucis de su pueblo desde la lejanía, hecho que le causaba dolor y no pocas veces un sentimiento profundo de frustración e impotencia. El Gobierno guatemalteco repetía la consigna de que la violencia en Guatemala se debía a la Iglesia. No solo la diócesis de Quiché sufrió esta realidad. De alguna manera, toda la Iglesia se vio envuelta en esta tragedia. A veces se llegaba a la conclusión de que cada pronunciamiento de la Iglesia en contra de la violencia y a favor de los derechos humanos concluía con el asesinato de algún sacerdote, o la expulsión y persecución de otros más. La Iglesia de Guatemala se vio reducida al silencio, era mejor actuar sin hablar. Hasta la misma Conferencia Episcopal optó por reunirse de manera discreta sin anunciar la sede donde se iban a reunir. Cientos de catequistas murieron, decenas de sacerdotes fueron expulsados o debieron dejar el país. Muchas casas religiosas eran registradas sin previo aviso. La Iglesia tuvo en el Gobierno militar del general Romeo Lucas uno de los momentos de mayor persecución de su historia; se repetían escenas de martirio que nos recuerdan casi en paralelo la realidad de los mártires de los primeros siglos bajo el Imperio romano. Por la vía del golpe de Estado se impuso al general E. Ríos Montt, que gobernó con brazo de hierro en años en los que se suceden las masacres y la práctica de la llamada "tierra arrasada" ${ }^{\text {. }}$. Una Iglesia que

15. J. M. Simon, Guatemala. Eternal spring, eternal tyranny. W. W. Norton \& Company, New York/London, 1985 (se está preparando la traducción al castellano, si bien es la calidad de sus fotos la que nos muestra la realidad de los años de la guerra).

16. Para estos años son indispensables dos grandes informes: (a) Proyecto Interdiocesano de Recuperación de la Memoria Histórica (REMHI), Guatemala: nunca más, 4 volúmenes, 
sufrió también en silencio su dolor, sin encontrar eco de su denuncia en los foros internacionales ${ }^{17}$.

Monseñor decide regresar a Guatemala muy discretamente, después del golpe de Estado del 23 de marzo de 1982, que llevó al poder al general Ríos Montt, en consideración a que su madre María Laura se encontraba gravemente enferma, y de hecho falleció días después. Pero no regresa a la diócesis de Quiché, donde se encontraba Mons. Pablo Urízar, administrador apostólico, tratando de rescatar algunas parroquias y haciendo acto de presencia con un pequeño grupo de sacerdotes. Monseñor Gerardi tampoco vive con su familia, sino que se "refugia" en una iglesia con el rango de "capellanía". Pasó casi dos años muy discretamente, de abril de 1982 a julio de 1984, cuando decide renunciar a la diócesis de Quiché para aceptar la propuesta del nuevo arzobispo de Guatemala, monseñor Próspero Penados del Barrio, como obispo auxiliar de la Arquidiócesis. Con el tiempo, la CEG le encomendó el cargo de secretario general y el arzobispo de Guatemala le encargó echar a andar los preparativos de un incipiente Plan Pastoral Arquidiocesano, que a la postre desembocaría en la realización del primer Sínodo Arquidiocesano.

Pero el corazón de monseñor Gerardi latía inquieto. Experimentaba en carne propia cómo la impunidad se adueñaba de Guatemala, la frustración de no poder hacer mucho por aliviar las injusticias cometidas contra la gente más humilde, el ver cómo la paz se condicionaba a la fuerza de las armas y cómo el derecho se retorcía cada día. Cada día tocaban a las puertas de los obispados de Guatemala, o de las parroquias, personas que pedían protección, ayuda en la desesperada realidad de verse amenazados y perseguidos... Fue así como el arzobispo Próspero Penados decide abrir una Oficina de Servicios Sociales del Arzobispado en 1989, de la que un año más tarde nacería la Oficina de Derechos Humanos del Arzobispado. Ambas le fueron encomendadas a monseñor Juan Gerardi, que con un equipo de abogados y profesionales pudieron poner en marcha la primera oficina para defender la vida en Guatemala, todavía dentro del enfrentamiento armado interno. Fue como romper el muro de la impunidad y ofrecer un camino de resistencia a la política de terror. Es importante recordar que esta decisión se da en el período del primer Gobierno democrático (1986-1990), pero en un país todavía militarizado, que estaba buscando los caminos de la paz y la reconciliación.

Viajó varios años a Ginebra para denunciar ante la Comisión de las Naciones Unidas para los Derechos Humanos las violaciones que se cometían contra la

Guatemala, 1998 (dirigido por monseñor Gerardi); (b) Comisión para el Esclarecimiento Histórico (CEH), Guatemala, memoria del silencio, Oficina de Servicios para Proyectos de las Naciones Unidas, Guatemala, 1999.

17. Pax Christi Internazionale, Nicaragua, El Salvador, Guatemala, Honduras. Rapporto sui Diritti Umani. Ed. EMI-Servizio Misionario, Bologna, 1982. 
vida, donde no llegaba como un político, sino como el hombre de Dios a quien le dolía ver cómo la imagen de cada ser humano asesinado era como ultrajar la imagen de Dios: "El sufrimiento de Cristo en su cuerpo místico es algo que nos debe hacer reflexionar. Es decir, si el pobre está fuera de nuestra vida, entonces quizás Jesús está fuera de nuestra vida"18.

\section{EI Informe REMHI}

El proceso de las negociaciones de paz iba caminando entre luces y sombras entre 1991 y 1994; en mayo de 1993, un nuevo golpe de Estado (disfrazado de "autogolpe") parecía aplazar las esperanzas de paz para el pueblo de Guatemala. El golpe significó el cambio de liderazgo en las negociaciones de paz. Se marginó a monseñor Rodolfo Quezada Toruño, conciliador entre las partes, y se pidió a las Naciones Unidas la conducción del proceso, que en 1994 consiguió algunos logros, entre otros, la firma del Acuerdo sobre Derechos Humanos y el Acuerdo sobre el Esclarecimiento Histórico. Del primero se siguió la instalación en el país de la Misión de las Naciones Unidas para Guatemala (MINUGUA), y del segundo la instalación de una comisión que investigase las violaciones a los derechos humanos en la larga guerra del enfrentamiento armado interno de 36 años.

Dada la experiencia que se tenía de los resultados en otras latitudes sobre la eficacia de estas comisiones, monseñor Gerardi, analizando la realidad, llegó a la conclusión de que en Guatemala una investigación similar, por ejemplo, a la de El Salvador no permitiría afianzar la justicia, fruto del perdón y la reconciliación, pilares de la paz. Nace así la idea, que no tiene precedentes en ninguna Iglesia de América Latina, de realizar una investigación patrocinada por la misma Iglesia, con sus mismos agentes, "promotores de la reconciliación", y ofrecer una base a dicha Comisión para el Esclarecimiento Histórico. El Acuerdo de las Naciones Unidas contemplaba una amnistía casi general, para dirigentes del Ejército, los Gobiernos de turno o la insurgencia revolucionaria que la investigación reconociera como hechores de violaciones a los derechos humanos. Según el Acuerdo para el Esclarecimiento Histórico, tampoco el informe daría los nombres de los responsables de dichas violaciones.

Monseñor Gerardi creía que con tales disposiciones la impunidad iba a adquirir carta de ciudadanía y las víctimas se sentirían con un nudo fuerte en sus gargantas y las manos atadas, sin base jurídica para reclamar sus derechos. Ciertamente, los crímenes contra la humanidad quedaban fuera del Acuerdo, pero ¿cómo reclamar justicia? También las familias individualmente podían recurrir a los tribunales, pero ¿a quiénes acusar?, ¿cuáles eran los nombres de las personas que violaron, desaparecieron o asesinaron a sus seres queridos?

18. Palabras de monseñor Juan Gerardi, dichas el 10 de marzo de 1998. 
Monseñor Gerardi reconocería a la hora de entregar los libros del REMHI: "Años de terror y muerte han desplazado y reducido al miedo y al silencio a la mayoría de guatemaltecos. La verdad es la palabra primera, la acción seria y madura que nos posibilita romper ese ciclo de violencia y muerte, y abrirnos a un futuro de esperanza y luz para todos" (24 de abril de 1998).

Creía este buen obispo de la reconciliación que en realidad la paz formal podría algún día lograrse, pero la justicia, el reconocimiento de los derechos de las víctimas, su resarcimiento, la verdad de lo sucedido en el pasado, quedaría enterrado para siempre si no se creaba el espacio para escuchar la palabra de las víctimas. Luchó por la realización de este informe, lo presentó a la Conferencia Episcopal, que luego de ver los pro y contra lo aprobó. Gerardi mantenía su posición: el perdón y la reconciliación no llegará si no se reconoce la verdad. Las víctimas tienen derecho a saber la verdad. Varias diócesis entraron con fuerza en el proyecto; entre otras, la diócesis del Quiché, en la que desde enero de 1987 era obispo monseñor Julio Cabrera Ovalle ${ }^{19}$, pero también Huehuetenango, San Marcos, Quetzaltenango, El Petén, La Verapaz, Izabal, Sololá... La investigación se realizó de 1995 a 1997. El resultado es el Informe REMHI, en 4 volúmenes, presentado el 24 de abril de 1998, que constituye un $7 \%$ de la información reunida. Se recolectaron 6,500 testimonios a lo largo y ancho de todo el país, que hablaban de más de 55,000 víctimas (de un total que pudo superar las 200,000). De acuerdo al Informe REMHI, entre 1980 y 1983 hubo en Guatemala casi 44,000 víctimas, que equivale al $80 \%$ del total que REMHI documentó. Entre 1981 y 1982 ocurrieron casi 300 masacres de las 422 que se pudieron documentar. De dichas masacres, 116 tuvieron más de 21 víctimas, y de otras 40 masacres se pudo documentar que tuvieron más de cien víctimas cada una.

En el departamento de Quiché fue donde se vivió con mayor intensidad el impacto de la violencia; el $57 \%$ de las víctimas, cuyos informes son recogidos por REMHI, se refieren a Quiché, y un 23\% a "Las Verapaces". En Quiché se perpetraron hechos violentos que causaron más de 31,400 víctimas. Para Guatemala, el Informe REMHI contabilizó 524 masacres, documentó 422; y de ellas, 263 se cometieron contra los pueblos del Quiché. Sólo en 1982 se perpetraron 120. De esas 263, el Ejército es responsable de 144; 90 fueron fruto de la colaboración entre el Ejército y grupos paramilitares; los paramilitares por su cuenta perpetraron 12; y la guerrilla es responsable de 14 de dichas masacres. Se sabe que estos datos no pueden dar cuenta de la totalidad de las violencias perpetradas contra el pueblo guatemalteco en esos años. En este informe, sin embargo,

19. J. Cabrera Ovalle, Memoria y testigos de Guatemala, Ediciones San Pablo, Guatemala, 2001; y Consuela a mi pueblo (tres volúmenes de homilías), editados en Guatemala. Ver igualmente el artículo "Monseñor Juan José Gerardi Conedera, profeta y mártir", en Conferencia Episcopal de Guatemala, Monseñor Juan Gerardi, testigo fiel de Dios, óp. cit., pp. 212-231. 
constaban lugares, nombres de los presuntos responsables, circunstancias de los hechos, de los que se puede seguir un proceso legal contra los victimarios ${ }^{20}$. Estos datos, por desgracia, nos ayudan a entender la causa por la que fue asesinado monseñor Juan Gerardi.

La presentación del Informe REMHI, que se llevó a cabo en la Catedral de Guatemala el 24 de abril de 1998, contó con la palabra de varias personalidades, entre ellas monseñor Julio Cabrera, obispo de Quiché, y monseñor Juan Gerardi, coordinador del Informe. En su discurso, monseñor Gerardi fue muy preciso en indicar la razón que llevó a la Iglesia a la elaboración del documento:

El Proyecto REMHI en el confluir del trabajo pastoral de la Iglesia es una denuncia, legítima, dolorosa que debemos de escuchar con profundo respeto y espíritu solidario. Pero también es un anuncio, una alternativa, para encontrar nuevos caminos de convivencia humana. Cuando emprendimos esta tarea nos interesaba conocer, para compartir, la verdad, reconstruir la historia de dolor y muerte, ver los móviles, entender el porqué y el cómo. Mostrar el drama humano, compartir la pena, la angustia de los miles de muertos, desaparecidos y torturados; ver la raíz de la injusticia y la ausencia de valores.

Este es un modo pastoral de hacer las cosas. Es trabajar a la luz de la fe, encontrar el rostro de Dios, la presencia del Señor. En todos estos acontecimientos, es Dios quien nos está hablando. Estamos llamados a reconciliar. La misión de Jesús es reconciliadora. Su presencia nos llama a ser reconciliadores en esta sociedad quebrada, tratando de ubicar víctimas y victimarios dentro de la justicia. Hay gente que murió por un ideal. Y los verdugos fueron muchas veces instrumentos. La conversión es necesaria, y nos toca abrir los espacios para estimularla. No se trata de aceptar los hechos simplemente. Es menester reflexionar y recuperar los valores.

Queremos contribuir a la construcción de un país distinto. Por eso recuperamos la memoria del pueblo. Este camino estuvo y sigue estando lleno de riesgos, pero la construcción del Reino de Dios tiene riesgos y sólo son sus constructores aquellos que tienen fuerza para enfrentarlos.

El discurso entero es una verdadera joya de la visión cristiana sobre la dignidad de la persona humana. Una guerra siempre coloca a la sociedad entera y a cada ser humano en particular en los límites de la degradación total y en la hipoteca de su futuro de esperanza, y así lo reconocía el obispo de los derechos humanos: "Abrirnos a la verdad, encarar nuestra realidad personal y colectiva no es una opción que se puede aceptar o dejar, es una exigencia inapelable para

20. Los volúmenes del Informe REMHI tienen este orden: vol. I: Impacto de la violencia (310 páginas); vol. II: Los mecanismos del horror (233 páginas); vol. III: El entorno histórico (373 páginas); vol. IV: Víctimas del conflicto (544 páginas). 
todo ser humano, para toda sociedad que pretenda humanizarse y ser libre. Nos sitúa ante nuestra condición más radical como personas: somos hijos e hijas de Dios, llamados a participar de la libertad del Padre".

Y termina su discurso reclamándose al orden de la creación primera: "La actualización y memoria de estos hechos dolorosos nos confrontan con una palabra original de nuestra fe: 'Caín, ¿dónde está tu hermano Abel? No sé, contestó. ¿Soy acaso el guardián de mi hermano? Replicó Yahvé: ¿qué has hecho? Se oye la sangre de tu hermano clamar desde el suelo hasta mí' (Gen 4, 9-10)".

\section{Justicia para un hombre justo}

Dos días después de la presentación del Informe REMHI, en la noche del 26 de abril, era salvajemente asesinado monseñor Juan Gerardi. El impacto de su muerte fue un mensaje claro para quienes estaban a favor de los Acuerdos de Paz, firmados a finales de 1996, pero sobre todo, contenía un mensaje claro contra aquellos que quisieran abrir el libro de la verdad. Su muerte cruel fue un mensaje de los sectores amparados en la impunidad.

Sin embargo, y también hay que decirlo, quienes planificaron y ejecutaron su muerte, la muerte de un obispo reconocido por su lucha a favor de los derechos humanos, pusieron en movimiento un impresionante aparato para que este nuevo hecho de violencia quedara impune. Una escena del crimen tremendamente distorsionada, noticias a los medios de prensa confusas y contradictorias, con las que se creaban nuevos escenarios de los hechos y se señalaban a presuntos asesinos entre individuos que pertenecen a la delincuencia común; ya desde el mismo día se quiso humillar la memoria del buen pastor, creando la sospecha de que su muerte se debía a un crimen pasional...

Sin embargo, las instancias de investigación oficiales caminaban por un lado, pero el sentimiento del pueblo era claro: "A monseñor Gerardi lo mataron por decir la verdad". Hasta se vio envuelto en los hechos un sacerdote, con lo que se quería crear aún más confusión indicando que se trataba de un crimen cuya causa estaba dentro de la misma Iglesia. Parecía un crimen perfecto; hasta se inculpó a un perro perteneciente al sacerdote que compartía tareas pastorales en la Parroquia de San Sebastián. Al final, las investigaciones, sobre todo dirigidas por los abogados de la Oficina de Derechos Humanos del mismo Arzobispado, fueron demostrando la falta de fundamento de cada una de las hipótesis formuladas por la fiscalía y el ministerio público, defendidas por sectores de gobierno y grupos de poder, y se fue abriendo luz a los verdaderos responsables de la muerte de monseñor Juan Gerardi: el Estado Mayor Presidencial del Gobierno del presidente Arzú, que unos años antes había firmado la paz (1996-2000). Este sector del Ejército era (ya se suprimió) un cuerpo autónomo dentro de las fuerzas de seguridad del Estado, encargado de la protección de las principales personalidades del Gobierno de la República. La presencia de miembros de este 
cuerpo a lo largo de varias décadas en hechos de violación a los derechos humanos, secuestros y asesinatos, ha sido demostrada en otros muchos casos, sin que las víctimas pudieran reclamar justicia.

El juicio para esclarecer la muerte violenta de monseñor Gerardi se inicia en marzo de 2001; en el banquillo de los acusados están un coronel retirado del Ejército, dos miembros del Estado Mayor Presidencial, un sacerdote y la cocinera de la casa del obispo. No son todos los que participaron. El 8 de junio de ese año, después del interrogatorio de los testigos, la sentencia dio 30 años de prisión a los militares y 20 al sacerdote; quedó libre la cocinera. La sentencia pide investigar al menos a una media docena de militares más de alto rango, a los que se les descubrió participación en el crimen. Con los recursos posteriores, los abogados de los militares consiguieron revocar la sentencia en segunda instancia, pero no ante la Corte Suprema de Justicia ni ante la Corte de Constitucionalidad. Dicha sentencia quedó en firme cinco años después. Está pendiente la continuidad del proceso $^{21}$.

Por su parte, la Iglesia de Guatemala, especialmente el actual arzobispo, cardenal Quezada Toruño, se ha mantenido firme en reclamar justicia para un hombre justo, como es el sentimiento de la Iglesia entera y de toda la ciudadanía. Ante los participantes al VII COMLA y II CAM, que se llevó a cabo en Guatemala a finales de noviembre de 2003, el arzobispo de Guatemala les aseguró: "Y ante todos ustedes, que representan tantas iglesias del mundo y tantas iglesias particulares de América Latina, haciéndome portavoz de mis hermanos los obispos de Guatemala y yo mismo, les puedo asegurar que no descansaremos luchando jurídicamente para esclarecer este asesinato... Y que no estén tranquilos los autores intelectuales o materiales, porque seremos la voz de su conciencia, para que estos hechos, como quería monseñor Gerardi, en Guatemala nunca más se repitan”.

\section{Comprometidos con su memoria y su legado}

La muerte de monseñor Gerardi nos golpeó el alma, fue la respuesta inhumana del sistema de muerte que él había combatido con la palabra de la verdad y la fuerza del Evangelio. Su memoria queda en nuestros corazones, y su legado es un estímulo constante para luchar por una Guatemala distinta ${ }^{22}$.

21. Una de las mejores investigaciones publicadas sobre este proceso es fruto del periodista guatemalteco-estadounidense Francisco Goldman, en su libro The art of political murder. Who killed the bishop?, Grove Press, New York, 2007. En mayo de 2009 se publicó la traducción en castellano, con un capítulo añadido sobre las investigaciones relativas al año 2008: El arte del asesinato político. ¿Quién mató al obispo?, Editorial Anagrama, Guatemala, 2009.

22. Con ocasión del $10^{\circ}$ aniversario, se realizó un seminario internacional en Guatemala del 23 al 25 de abril de 2008, cuya memoria lleva por título "Construyendo la paz desde la verdad". 
En el décimo primer aniversario del martirio del obispo Gerardi, don Pedro Casaldáliga, desde Brasil, le dedicó estos versos:

Tu muerte, buen pastor, no ha sido en vano. Guiados por tu ejemplo, nosotros seguiremos forjando la verdad y la justicia, dando la voz al canto enmudecido, dando esperanza al Pueblo caminante, dando la vida al Reino de los pobres. 